\title{
Measuring the potential implications of introducing a cap and share scheme in Ireland to reduce green house gas emissions
}

\author{
David McNamara and Brian Caulfield* \\ *Department of Civil, Structural and Environmental Engineering \\ Trinity College Dublin \\ Dublin 2 \\ Ireland \\ Tel: +35318962534 \\ Fax: +35316773072 \\ Email: brian.caulfield@tcd.ie
}

\begin{abstract}
This paper examines some of the potential impacts of introducing a cap and share scheme in Ireland, whereby a cap or limit is placed on national $\mathrm{CO}_{2}$ emissions and individuals are allocated an annual $\mathrm{CO}_{2}$ allowance. The research presented in this paper focuses on travel-toworks trips specifically. $\mathrm{CO}_{2}$ emissions for these annual work trips are calculated and a cap is determined based on these results. Cap levels are set based on average emissions and a 20\% reduction in average emissions as per Ireland's reduction targets. A national and Dublin only cap are examined and the results are presented as a means of comparison. Binary logistic models are used to determine the socio-economic characteristics of individuals who fall above and below the cap. The results demonstrate the importance of car ownership, journey distance, mode choice, and household composition in determining whether a commuter is above or below a cap. Many commuters who fall above the cap are likely drive to work over long distances, have dependent children in their household and own more than one car.
\end{abstract}

\section{Introduction}

Cap and share schemes set a limit on the quantity of green house gases (GHG), which can be emitted in an economy annually. This cap is enforced by issuing permits to GHG emitters in the economy. If an entity exceeds their allowance they can purchase permits from entities that have a surplus. This creates a market for GHG's that is operated and regulated by government. The different configurations of such schemes are discussed in more detail in the subsequent sections. Under Kyoto guidelines, Ireland's GHG emissions must not exceed 1990 levels by more than $12 \%$ by 2012. In 2008, Environmental Protection Agency (EPA) published a report that annual emissions were reducing but not at a fast enough rate to meet Kyoto targets in 2012 (EPA, 2008). The Irish government has outlined a number of policy objectives to promote sustainability to meet Kyoto targets (Department of Transport, 2009), particularly in public transportation. These objectives include alleviating urban sprawl by limiting single house developments whilst promoting sustainable high density developments, investing significantly in public transportation and promoting work at home policies such as e-working.

The Irish government has also commissioned a number of reports into the viability of a cap and share scheme. Research has focused on the national implementation of an emissions cap across all sectors of the economy. This paper will investigate the impact of a 
cap on individuals who undertake daily travel-to-work trips under a personal cap and share scheme. This paper is organised into five sections including this introduction. It will proceed with an explanation of cap and share and a review of the relevant literature, an explanation of the methodologies used, results of the analysis and conclusions to be drawn from the research.

\section{Cap and share}

Internationally literature relating to cap and share has reached a consensus that such a scheme can effectively reduce GHG emissions and is less regressive than a carbon tax (SDC, 2008; Starkey and Anderson, 2005; Harwatt, 2008). Debate therefore has focused on the technical implementation of a potential scheme. Fleming (1997) was one of the first authors to advocate the use of "tradable quotas" in reducing carbon emissions. Such a scheme distributed free allowances to end-users and created an auction process for businesses and public sector bodies to purchase quotas. This approach is an example of a downstream cap. Subsequent studies have advocated an upstream cap (Fleming, 1997; Tietenberg, 2001; Millard-Ball, 2008). An upstream cap allocates permits to importers of energy i.e. oil refineries, fuel importers etc. Millard-Ball (2008) recommended the use of such a scheme due to its administrative simplicity and complete coverage of a small group of energy importers. This is a view shared by California's Market Advisory Committee (MAC). The MAC was created to study market-based mechanisms to reduce GHG emissions in the US state. The MAC recommended an upstream cap due to reduced administrative costs in comparison to a downstream cap and the presence of fewer agents in the market (California Air Resources Board, 2007).

Advocates of a downstream cap argue that durable reductions in GHG emissions can only be achieved through the behavioural changes associated with a downstream cap on consumers (Fleming, 1997; Fawcett, 2005; Niemeier, 2008). The potential impact of an upstream cap is increased fuel prices, which would be in effect a tax on consumers, creating inequitable market outcomes (Fleming, 1997). Niemeier (2008) proposed a household GHG cap and trade (HHCT) system which would target consumers with four key elements: a state allocation to households, household to household trading, households to utility company credit transfers, and utility companies to government credit transfers. The proposed system expanded on Fleming's model in allocating free allowances to consumers while granting regulation of the scheme to energy utility companies. This system is found to be more equitable than carbon taxes and an upstream cap. Millard-Ball (2008) identified five options, which would incorporate the transportation sector into a cap and share scheme. An upstream and downstream cap was discussed in addition to a vehicle manufacturer based scheme. This manufacturer scheme was rejected however as tailpipe standards appear to achieve the same results. An offset scheme is also examined which would not explicitly cap transport emissions but allow developers, municipalities transit agencies etc. to put forward transportation projects that offset emissions from the stationary sector. Millard-Ball (2008) found that the favoured scheme was a 'municipal mobility manager' scheme, which would hold local governments responsible for emissions cap target, providing penalties for exceeding the cap and incentives for reducing emissions. This provides the benefits of an offset scheme without the administrative costs.

As this paper is concerned with the end users of road transport, the impacts of a potential downstream cap on transport emissions will be studied. End users are studied in this case because the dataset involved tabulates end user activity and therefore lends itself to studying the effects of a downstream cap. A potential downstream cap would allocate permits to 
individuals to emit $\mathrm{CO}_{2}$ equally to transport uses. Research in the transportation sector is limited, with many authors suggesting a cap on household energy use only. This is ignoring the importance of the transport sector's contribution to GHG emissions. The Sustainable Development Council (2008) recommended an initial cap on the transport sector applied downstream. This cap was compared to other carbon reduction measures and the potential effects of a cap were discussed. A minority of lower income households were predicted to be worse off from such a scheme and inequities between rural and urban dwellers were predicted to arise. A research requirement arises in studying the effects of the inequalities created by cap and share. The Sustainable Development Council report did not outline the important socio-economic characteristics of individuals who would be affected by the cap, instead concentrating on comparing income groups across the economy. This paper will investigate the relevant socio-economic groups. Recent research has dealt somewhat with socioeconomic and equity issues. Wadud (2010) found that the majority of allocation strategies were progressive. A caveat of this conclusion was that the effects on poor rural commuters were most likely regressive without allocations being adjusted accordingly. Raux and Marlot (2005) stressed the importance of an equal allocation of $\mathrm{CO}_{2}$ permits to mitigate equity issues together with a tailored allocation of permits based on socio-economic characteristics. Recent literature has suggested further research is needed in the area of cap and share and associated energy poverty and equity issues (Brand and Preston, 2010). This paper does not deal with the technical implementation of a national cap rather it studies the socio-economic impacts effects of a cap on the daily trip to work.

\section{Methodology}

The dataset used in this paper is a subset of the Irish Census of Population, 2006 relating to people's daily trips to work, school and college. This dataset is named the place of work census of anonymised records (POWCAR). It contains information on trips of 1,834,472 individuals in Ireland. It is the most extensive national travel dataset available at present in the country. This dataset also contains information on the distance travelled, socio-economic grouping, occupation, household structure, and modes of transport. As this paper is concerned with a potential cap on personal travel emissions, a method for calculating individual's annual emissions must be determined initially. Once this is calculated a cap can be set on emissions. Regression analysis can then be used to study the socio-economic characteristics of individuals who lie above this level.

\subsection{Emissions Estimation}

This section of the paper presents the methods by which the relevant $\mathrm{CO}_{2}$ emissions were estimated. Emission factors calculated in Walsh et al. (2008) are used in this particular paper. These Irish emission factors are inclusive of average peak hour occupancy rates for the relevant modes of public transport and are measured in kilograms of $\mathrm{CO}_{2}$ per passenger kilometre. Emission factors for motorized transport are calculated based on fuel consumption for a range of engine sizes. Emission factors for electric powered public transport are calculated based on energy usage converted to carbon and distance travelled per year. These factors are presented in Table 1. 
Table 1 Occupancy rates and emissions factors

\begin{tabular}{|l|l|l|}
\hline Mode & Occupancy & kg CO2/Pass km \\
\hline Train & 945 & 0.011 \\
\hline Tram & 235 & 0.064 \\
\hline Intercity bus & 57 & 0.015 \\
\hline Dublin bus & 90 & 0.016 \\
\hline Private car & 1.4 & 0.12 \\
\hline
\end{tabular}

Factors taken for Walsh et al. (2008)

The following equation was used to calculate the $\mathrm{CO}_{2}$ emissions generated by travel-to-work trips,

Equation 1

$C \mathrm{O}_{2}=E F * 2 * V K M * 215$

where VKM is the total number of kilometres travelled by the mode of transport in question and $\mathrm{EF}$ is the emission factor per passenger kilometres travelled by that mode. This was then doubled to calculate the emissions for a return journey and multiplied by 215 to calculate annual emissions. This figure of 215 days is the average working year in Ireland. Average emissions can be calculated and a potential cap on personal emissions set.

\subsection{Setting the Cap}

The cap levels chosen in this case is based on the emissions calculations only as a starting point to determine the potential socio-economic characteristics of individuals above and below the cap. An average emissions level was chosen as the measure of the cap, which is inline with previous studies, as it enables and analyses socio-economic characteristics of those above and below the cap. As the data used in this paper is taken from the 2006 Census, the cap is set at 2006 emissions levels. The potential allocation of permits to individuals would be distributed at zero cost and equally to all users of transport as has been recommended in previous literature. The initial cap in the model for both the Dublin and the national datasets is set at the average annual emissions calculated. The cap is then lowered by $20 \%$ in both datasets. The purpose of lowering the cap is to ascertain if Ireland is to meet its GHG targets, which would result in approximately a 20\% cut in 2006 GHG levels, how this would impact upon society, and what sectors would be most impacted. Two caps are examined in this paper: a national cap and a Dublin only cap. This results in eight subsections of the population being examined - those above and below the average cap and those above and below average cap less $20 \%$ both nationally and in the Dublin only model. Table 2 presents the percentage of commuters who would fall above and below a cap. A cap based on average emissions calculated would leave $31 \%$ of commuters above the cap in Dublin, which is higher than the national average of $26 \%$. Lowering the cap further by $20 \%$ would leave $36 \%$ of commuters above the cap in Dublin compared to 32\% nationally. 
Table 2 Percentage of commuters over the cap

\begin{tabular}{|l|l|l|l|l|}
\hline Cap based on average emissions \\
\hline & Dublin & Dublin \% & National & National \% \\
\hline Above Cap & 139,072 & 31 & 399,979 & 26 \\
\hline Below Cap & 308,544 & 69 & $1,144,855$ & 74 \\
\hline Total & 369,318 & 100 & $1,544,834$ & 100 \\
\hline \multicolumn{7}{|l|}{} \\
\hline Cap 20\% below average emissions & \multicolumn{3}{l|}{} \\
\hline \multicolumn{7}{|l|}{} & & National \% \\
\hline Above Cap & Dublin & Dublin \% & National & 32 \\
\hline Below Cap & 161,407 & 36 & 500,109 & 68 \\
\hline Total & 286,209 & 64 & $1,044,725$ & 100 \\
\hline
\end{tabular}

Figures 1 and 2 graph the number of mechanised trips taken both in Dublin and nationally respectively. The numbers of trips are split between those trips that fall below the cap and those over the cap. The results presented in these figures show that approximately 15 million or $16 \%$ of all drive alone trips were above the cap in Dublin per annum. Nationally it was found the over 64 million drive alone trips per annum (30\%) were above the cap. It was found that nationally $89 \%$ (20million) of all lorry or van trips we found to be above the cap. Of the public transport modes examined rail trips were the only trips found to be in some cases over the cap limit. The results show that $11 \%$ of rail trips nationally were over the cap limit whereas just 5\% of these trips in Dublin were above the cap limit.

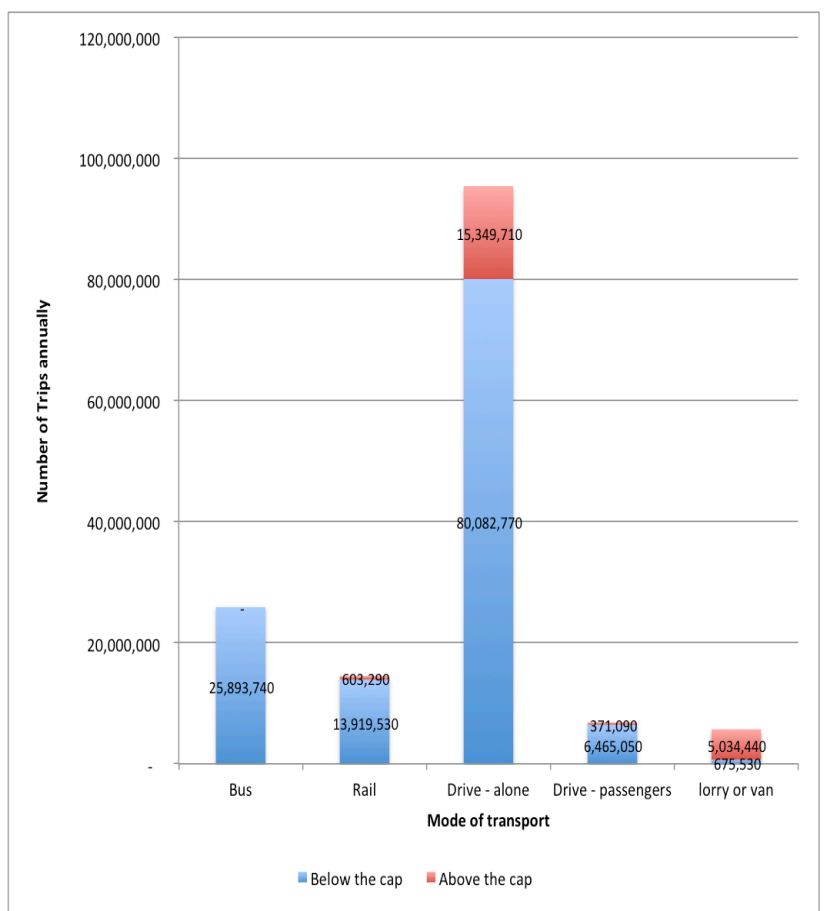

Figure 1 Annual Dublin Trips 


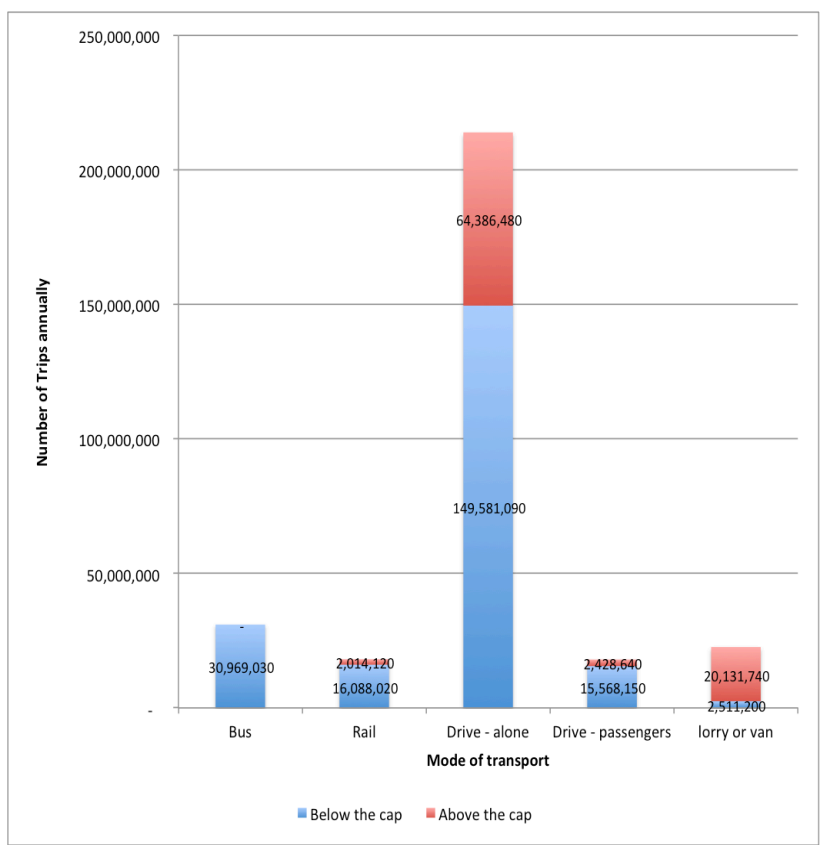

Figure 2 Annual National Trips

\subsection{Logistic model formulation}

This model is based on a binary logistic regression as outlined in Washingtonet et al. (2003). Consider an event $\mathrm{Y}$, which in this case is an individual emitting $\mathrm{CO}_{2}$ above a predetermined cap. The probability of a person being above this cap is $\mathrm{P}(\mathrm{Y})$ in the model and the resulting outcome is equal to 1 . The dependent variable is the $\log$ of the odds ratio of the event $\mathrm{Y}$ occurring or the logit of $\mathrm{Y}$ as shown in equation 2.

Equation 2

$$
\operatorname{Logit}(\mathrm{Y})=\ln \left(\frac{\hat{\mathrm{Y}}}{1-\hat{\mathrm{Y}}}\right)=\beta_{0}+\beta_{i} X_{i}
$$

where $\beta_{0}$ is the model constant and $\beta_{i}$ are the parameter estimates for the set of socioeconomic independent variables $\left(X_{i}, i=1, \ldots, \mathrm{n}\right) . \hat{\mathrm{Y}}$ is the predicted probability of the event which takes binary values of 1 (continue analysis) or 0 (stop the analysis). Thus when an independent variable $X_{i}$ increases by one unit, all other factors remain constant as shown in equation 3.

\section{Equation 3}

$$
\begin{aligned}
& \left(\frac{\hat{Y}}{1-\hat{Y}}\right)=E X P^{\beta_{0}} E X P^{\beta_{i}\left(x_{i}+1\right)}=E X P^{\beta_{0}} E X P^{\beta_{0}} E X P^{\beta_{i} X_{i}} E X P^{\beta_{i}} \\
& =\left(\frac{\hat{Y}}{1-\hat{Y}}\right) E X P^{\beta_{i}}
\end{aligned}
$$

The factor $E X P^{\beta_{i}}$ is the odd ratio (OR) ranging from zero to infinity. It indicates the relative amount by which the odds of the outcome increases or decreases when the value of 
the independent variable $X_{i}$ increases by one unit. A Wald test is used to test the significance of each parameter $(\beta)$ in the model as shown in equation 4 .

\section{Equation 4 \\ $z=\frac{\hat{\beta}}{S E}$}

The Z-value is then squared, creating a Wald statistic with a chi-squared distribution. Table 3 presents the set of independent variables estimated in the logistic model. In this case four models are estimated, two each for the national dataset and Dublin dataset. Two models are based on a cap calculated from average annual emissions and two based on average annual emissions less $20 \%$. Table 3 defines each of the variables examined in the logit models. 
Table 3 Details of variables examined

\begin{tabular}{|c|c|}
\hline Variable & Definition \\
\hline \multicolumn{2}{|l|}{ Distance } \\
\hline Commute Distance: $0-5 \mathrm{~km}$ & $=1$ if Distance: $0-5 \mathrm{~km}$ \\
\hline Commute Distance: $6-10 \mathrm{~km}$ & $=1$ if Distance: $6-10 \mathrm{~km}$ \\
\hline Commute Distance: $11-15 \mathrm{~km}$ & $=1$ if Distance: $11-15 \mathrm{~km}$ \\
\hline Commute Distance: $16-20 \mathrm{~km}$ & $=1$ if Distance: $16-20 \mathrm{~km}$ \\
\hline Commute Distance: $21-30 \mathrm{~km}$ & $=1$ if Distance: $21-30 \mathrm{~km}$ \\
\hline Commute Distance: $31-40 \mathrm{~km}$ & $=1$ if Distance: $31-40 \mathrm{~km}$ \\
\hline Commute Distance: $41+\mathrm{km}$ & $($ Reference category $=$ Distance: $41+\mathrm{km})$ \\
\hline \multicolumn{2}{|l|}{ Age } \\
\hline Age: $15-24$ & $=1$ if Age: $15-24$ \\
\hline Age: $25-34$ & $=1$ if Age: $25-34$ \\
\hline Age: $35-44$ & $=1$ if Age: $35-44$ \\
\hline Age: $45-54$ & $=1$ if Age: $45-54$ \\
\hline Age: $55-64$ & $=1$ if Age: $55-64$ \\
\hline Age: $65-74$ & $=1$ if Age: $65-74$ \\
\hline Age: $75+$ & $($ Reference category $=$ Age: $75+$ ) \\
\hline \multicolumn{2}{|l|}{ Gender } \\
\hline Gender: Male & $=1$ if Gender: male \\
\hline Gender: Female & ( Reference category $=$ Gender: Female) \\
\hline \multicolumn{2}{|l|}{ Socio-economic group } \\
\hline Socio-economic group: Employers and managers & $=1$ if Socio-economic group: Employers and managers \\
\hline Socio-economic group: Higher professional & $=1$ if Socio-economic group: Higher professional \\
\hline Socio-economic group: Lower professional & $=1$ if Socio-economic group: Lower professional \\
\hline Socio-economic group: Non-manual & $=1$ if Socio-economic group: Non-manual \\
\hline Socio-economic group: Manual skilled & $=1$ if Socio-economic group: Manual skilled \\
\hline Socio-economic group: Semi skilled & $=1$ if Socio-economic group: Semi skilled \\
\hline Socio-economic group: Unskilled & $=1$ if Socio-economic group: Unskilled \\
\hline Socio-economic group: Self employed & $=1$ if Socio-economic group: Self employed \\
\hline Socio-economic group: Farmers & $=1$ if Socio-economic group: Farmers \\
\hline Socio-economic group: Agricultural workers & $=1$ if Socio-economic group: Agricultural workers \\
\hline Socio-economic group: Other & ( Reference category = Socio-economic group: Other) \\
\hline \multicolumn{2}{|l|}{ Number of cars/vans } \\
\hline Number of Cars/vans: 1 & $=1$ if number of cars/vans: 1 \\
\hline Number of Cars/vans: 2 & $=1$ if number of cars/vans: 2 \\
\hline Number of Cars/vans: 3 & $=1$ if number of cars/vans: 3 \\
\hline Number of Cars/vans: 4 or more & $=1$ if number of cars/vans: 4 or more \\
\hline Number of Cars/vans: None & ( Reference category = Number of Cars/vans: None) \\
\hline \multicolumn{2}{|l|}{ Household Composition } \\
\hline Single & $=1$ if Single \\
\hline Lone Parent with Children & $=1$ if Lone Parent with Children \\
\hline Lone Parent no Children under 19 & $=1$ if Lone Parent no Children under 19 \\
\hline Couple with Children & $=1$ if Couple with Children \\
\hline Couple no Children under 19 & $=1$ if Couple no Children under 19 \\
\hline Couple no Children & $=1$ if Couple no Children \\
\hline Other Households & $\begin{array}{l}\text { (Reference category }=\text { Household Composition: Other } \\
\text { Households) }\end{array}$ \\
\hline
\end{tabular}

\section{RESULTS AND ANALYSIS}

\subsection{Setting the cap}

This section of the paper presents the results of the various analyses carried out. Table 4 presents the annual emissions calculated for trips in Dublin city. As expected driving a car 
accounts for the bulk of emissions due to $50 \%$ of trips being taken by car. Table 5 presents a breakdown of commute travel for the national dataset and the Dublin sample. The percentage difference column (D) represents Dublin having a higher percentage of total modal share while $(\mathrm{N})$ represents the national figure being higher. Driving accounts for $58.1 \%$ of trips nationally while $9 \%$ use public transport. Driving a car in Dublin accounts for $49 \%$ of trips in comparison to $21.8 \%$ of trips made by public transport. This result is much higher than the national average due to the availability of public transport in Dublin city. Another interesting result is that nationally more people work from home (3.1\%) than in Dublin (1.5\%). Table 6 presents the average emissions per commuter on a daily and annual basis. As is expected average emissions per capita are lower in Dublin city compared to the national average. These values will be used as the base point to set the cap in the model.

Table 4 Emissions calculations for Dublin

\begin{tabular}{|l|l|l|l|l|}
\hline Means of Travel & Daily km travelled & Annual Km travelled & $\begin{array}{l}\text { CO2 Emissions } \\
\left(\mathbf{K g}_{\mathbf{~ C O}} \mathbf{k m}\right)\end{array}$ & $\begin{array}{l}\text { of Total } \\
\text { Emissions }\end{array}$ \\
\hline Bus & $1,196,986$ & $257,351,990$ & $4,117,632$ & 2.29 \\
\hline Rail & $1,551,486$ & $333,569,490$ & $3,669,264$ & 2.04 \\
\hline Motorcycle & 143,192 & $30,786,280$ & $3,694,354$ & 2.05 \\
\hline Car-Driver & $5,841,858$ & $1,255,999,470$ & $150,719,936$ & 83.83 \\
\hline Car-Passenger & 346,614 & $74,522,010$ & $6,334,371$ & 3.52 \\
\hline Lorry/Van & $60,250,740$ & $11,086,136$ & 6.17 \\
\hline
\end{tabular}

Table 5 Modal split of commuters

\begin{tabular}{|c|c|c|c|c|c|c|}
\hline \multicolumn{3}{|l|}{ Dublin } & \multicolumn{4}{|l|}{ National } \\
\hline Mode & $\mathbf{N}$ & $\%$ & Mode & $\mathbf{N}$ & $\%$ & \% Difference \\
\hline Walk & 70,080 & 13.2 & Walk & 197,622 & 10.9 & 2.3(D) \\
\hline Cycle & 20,602 & 3.9 & Cycle & 35,310 & 1.9 & $2(\mathrm{D})$ \\
\hline Public transport & 116,350 & 21.8 & Public transport & 164,066 & 9.0 & $12.8(\mathrm{D})$ \\
\hline Motorcycle & 39,534 & 1.2 & Motorcycle & 12,678 & 0.7 & $0.5(\mathrm{D})$ \\
\hline Driving & 260,754 & 49 & Driving & $1,052,795$ & 58.1 & $9.1(\mathrm{~N})$ \\
\hline Driving - Passenger & 19,977 & 3.8 & Driving - Passenger & 102,483 & 5.7 & $1.9(\mathrm{~N})$ \\
\hline Lorry or van & 19,239 & 3.6 & Lorry or van & 138,208 & 7.6 & $4(\mathrm{~N})$ \\
\hline Other means & 1,028 & 0.2 & Other means & 6,228 & 0.3 & $0.1(\mathrm{~N})$ \\
\hline Work from home & 8,218 & 1.5 & Work from home & 56,897 & 3.1 & $1.6(\mathrm{~N})$ \\
\hline NA & 9,364 & 1.8 & NA & 45,634 & 2.5 & $0.7(\mathrm{~N})$ \\
\hline Total & 532,219 & 100.0 & Total & $1,811,921$ & 100.0 & \\
\hline
\end{tabular}

Table 6 Average emissions per individual ( $\mathrm{Kg} \mathrm{CO} 2 \mathrm{KM}$ )

\begin{tabular}{|l|l|l|}
\hline & Dublin & National \\
\hline Daily $\mathrm{CO}_{2}$ & 2.13 & 4.42 \\
\hline Annual $\mathrm{CO}_{2}$ & 458.5 & 952.1 \\
\hline
\end{tabular}

\subsection{Descriptive statistics}

Table 7 presents descriptive statistics associated with the variables of interest across the four models. The number of individuals above and below the cap is tabulated and each subgroup's percentage share of the total number of commuters is also tabulated. The majority of commuters who travel less than $10 \mathrm{~km}$ regardless of the mode of transport used would be under a cap based on average emissions and a cap lowered by $20 \%$. These individuals account for over $50 \%$ of trips in the dataset representing a sizable proportion of individuals who would not be affected by the introduction of a cap. This result demonstrates that distance travelled, as one would expect, has the greatest impact on if an individual is above or below the cap. The age profile of the largest group above the cap is 25-34 year olds. However, the majority of this age group were found to be under the cap at both levels nationally and in Dublin. 
The gender variable shows more males falling above the cap than females across all four models; this was shown to be highest in the Dublin results. The socio-economic group variables relate to the professions of the individuals examined. The results show little difference in the breakdown of individuals above and below the cap. Employers \& managers are consistently the largest group above the cap, particularly in Dublin. Non-manual workers are shown to be the largest group of individuals consistently under the cap.

The cars/vans variable shows that the largest group above the cap are commuters who own two vehicles. The largest groups below the cap are commuters owning one vehicle, as one would expect. Household composition is an important variable in determining the socioeconomic characteristics of individuals. An individual's travel behaviour will inevitably be constrained by the number of dependent children present and this is evident in the results. The largest group above the cap in all four models are couples with dependent children. The means of travel variable shows that the vast majority of commuters drive to work. However, the majority of drivers fall below the cap. This indicates that many journeys are over short distances. One of the variables that would have been desirable to examine in this section is individuals' income. Unfortunately this variable is not provided in the POWCAR dataset and therefore it is not possible to draw conclusions on how income might impact the cap and share scheme. 
Table 7 Descriptive statistics associated with variables of interest

\begin{tabular}{|c|c|c|c|c|c|c|c|c|c|c|c|c|c|c|c|c|}
\hline \multirow{3}{*}{$\begin{array}{l}\text { Variable } \\
\text { Distance }\end{array}$} & \multicolumn{4}{|c|}{ National cap average emissions } & \multicolumn{4}{|c|}{ National cap lowered by $20 \%$} & \multicolumn{4}{|c|}{ Dublin cap average emissions } & \multicolumn{4}{|c|}{ Dublin cap lowered by $20 \%$} \\
\hline & \multicolumn{2}{|c|}{ Above cap } & \multicolumn{2}{|c|}{ Below cap } & \multicolumn{2}{|c|}{ Above cap } & \multicolumn{2}{|c|}{ Below cap } & \multicolumn{2}{|c|}{ Above cap } & \multicolumn{2}{|c|}{ Below cap } & \multicolumn{2}{|c|}{ Above cap } & \multicolumn{2}{|c|}{ Below cap } \\
\hline & $\mathbf{N}$ & $\%$ & $\mathbf{N}$ & $\%$ & $\mathbf{N}$ & $\%$ & $\mathbf{N}$ & $\%$ & $\mathbf{N}$ & $\%$ & $\mathbf{N}$ & $\%$ & $\mathbf{N}$ & $\%$ & $\mathbf{N}$ & $\%$ \\
\hline $0-5 \mathrm{~km}$ & 8,693 & 2 & 517,330 & 50 & 12,413 & 2 & 513,610 & 55 & 2,925 & 2 & 167,971 & 59 & 2,925 & 2 & 167,971 & 64 \\
\hline $6-10 \mathrm{~km}$ & 22,059 & 6 & 289,106 & 28 & 22,059 & 4 & 289,106 & 31 & 38,454 & 28 & 87,808 & 31 & 55,183 & 34 & 71,079 & 27 \\
\hline $11-15 \mathrm{~km}$ & 12,241 & 3 & 146,430 & 14 & 59,154 & 12 & 99,517 & 11 & 37,281 & 27 & 18,461 & 7 & 41,720 & 26 & 14,022 & 5 \\
\hline $16-20 \mathrm{~km}$ & 75,063 & 19 & 65,086 & 6 & 117,890 & 24 & 22,259 & 2 & 28,846 & 21 & 5,963 & 2 & 29,954 & 19 & 4,855 & 2 \\
\hline $21-30 \mathrm{~km}$ & 112,503 & 28 & 14,603 & 1 & 118,490 & 24 & 8,616 & 1 & 18,707 & 13 & 2,122 & 1 & 18,707 & 12 & 2,122 & 1 \\
\hline $31-40 \mathrm{~km}$ & 69,418 & 17 & 3,199 & 0 & 70,101 & 14 & 2,516 & 0 & 7,333 & 5 & 583 & 0 & 7,333 & 5 & 583 & 0 \\
\hline $41+\mathrm{km}$ & 100,002 & 25 & 3,257 & 0 & 100,002 & 20 & 3,257 & 0 & 5,526 & 4 & 369 & 0 & 5,585 & 3 & 310 & 0 \\
\hline \multicolumn{17}{|l|}{ Age } \\
\hline $15-24$ & 38,598 & 10 & 153,499 & 13 & 48,641 & 10 & 143,456 & 14 & 11,161 & 8 & 47,006 & 15 & 13,142 & 8 & 45,025 & 16 \\
\hline $25-34$ & 133,387 & 33 & 337,260 & 29 & 164,818 & 33 & 305,829 & 29 & 46,820 & 34 & 106,482 & 35 & 53,936 & 33 & 99,366 & 35 \\
\hline $35-44$ & 115,735 & 29 & 276,654 & 24 & 143,541 & 29 & 248,848 & 24 & 37,457 & 27 & 66,220 & 21 & 43,122 & 27 & 60,555 & 21 \\
\hline $45-54$ & 76,514 & 19 & 231,668 & 20 & 97,093 & 19 & 211,089 & 20 & 27,714 & 20 & 54,746 & 18 & 32,384 & 20 & 50,076 & 17 \\
\hline $55-64$ & 32,996 & 8 & 127,119 & 11 & 42,447 & 8 & 117,668 & 11 & 14,266 & 10 & 30,032 & 10 & 16,865 & 10 & 27,433 & 10 \\
\hline $65-74$ & 2,521 & 1 & 15,988 & 1 & 3,253 & 1 & 15,256 & 1 & 1,482 & 1 & 3,537 & 1 & 1,758 & 1 & 3,261 & 1 \\
\hline $75+$ & 228 & 0 & 2,667 & 0 & 316 & 0 & 2,579 & 0 & 172 & 0 & 521 & 0 & 200 & 0 & 493 & 0 \\
\hline \multicolumn{17}{|l|}{ Gender } \\
\hline Male & 271,016 & 68 & 598,798 & 52 & 326,553 & 65 & 543,261 & 52 & 90,484 & 65 & 151,667 & 49 & 102,587 & 64 & 139,564 & 49 \\
\hline Female & 128,963 & 32 & 546,057 & 48 & 173,556 & 35 & 501,464 & 48 & 48,588 & 35 & 156,877 & 51 & 58,820 & 36 & 146,645 & 51 \\
\hline \multicolumn{17}{|l|}{ Socio-economic group } \\
\hline Employers \& managers & 73,998 & 19 & 171,537 & 15 & 91,472 & 18 & 154,063 & 15 & 33,524 & 24 & 50,682 & 16 & 38,878 & 24 & 45,328 & 16 \\
\hline Higher professional & 29,341 & 7 & 86,271 & 8 & 37,474 & 7 & 78,138 & 7 & 15,291 & 11 & 33,118 & 11 & 18,236 & 11 & 30,173 & 11 \\
\hline Lower professional & 58,700 & 15 & 156,664 & 14 & 75,521 & 15 & 139,843 & 13 & 20,719 & 15 & 48,471 & 16 & 24,698 & 15 & 44,492 & 16 \\
\hline Non-manual worker & 70,956 & 18 & 313,996 & 28 & 95,019 & 19 & 295,933 & 28 & 27,945 & 20 & 96,538 & 31 & 33,603 & 21 & 90,880 & 32 \\
\hline Manual skilled & 73,637 & 18 & 111,820 & 10 & 86,994 & 17 & 98,463 & 9 & 18,617 & 13 & 20,720 & 7 & 20,396 & 13 & 18,941 & 7 \\
\hline Semi skilled & 35,870 & 9 & 125,248 & 11 & 46,136 & 9 & 114,982 & 11 & 8,811 & 6 & 25,903 & 8 & 9,991 & 6 & 24,723 & 9 \\
\hline Unskilled workers & 14,041 & 4 & 45,096 & 4 & 16,898 & 3 & 42,239 & 4 & 2,902 & 2 & 11,960 & 4 & 3,250 & 2 & 11,612 & 4 \\
\hline Self employed & 26,361 & 7 & 37,686 & 3 & 29,409 & 6 & 34,638 & 3 & 6,475 & 5 & 7,737 & 3 & 6,918 & 4 & 7,294 & 3 \\
\hline
\end{tabular}




\begin{tabular}{|c|c|c|c|c|c|c|c|c|c|c|c|c|c|c|c|c|}
\hline Farmers & 4,336 & 1 & 41,742 & 4 & 5,282 & 1 & 40,796 & 4 & 211 & 0 & 578 & 0 & 229 & 0 & 560 & 0 \\
\hline Agricultural workers & 1,958 & 0 & 8,065 & 1 & 2,440 & 0 & 7,583 & 1 & 127 & 0 & 411 & 0 & 137 & 0 & 401 & 0 \\
\hline Other & 10,781 & 3 & 40,730 & 4 & 13,464 & 3 & 39,047 & 4 & 4,450 & 3 & 12,426 & 4 & 5,071 & 3 & 11,805 & 4 \\
\hline \multicolumn{17}{|l|}{ Number of cars/vans } \\
\hline One & 86,956 & 22 & 371,492 & 32 & 111,679 & 22 & 346,769 & 33 & 41,746 & 30 & 114,345 & 37 & 49,205 & 30 & 106,886 & 37 \\
\hline Two & 222,579 & 56 & 460,594 & 40 & 276,182 & 55 & 406,991 & 39 & 71,050 & 51 & 97,627 & 32 & 81,558 & 51 & 87,119 & 30 \\
\hline Three & 52,774 & 13 & 117,641 & 10 & 65,698 & 13 & 104,717 & 10 & 16,046 & 12 & 23,760 & 8 & 18,488 & 11 & 21,318 & 7 \\
\hline Four or more & 28,475 & 7 & 51,732 & 5 & 34,966 & 7 & 45,241 & 4 & 5,680 & 4 & 7,168 & 2 & 6,453 & 4 & 6,395 & 2 \\
\hline None & 4,665 & 1 & 125,678 & 11 & 5,905 & 1 & 124,438 & 12 & 2,766 & 2 & 60,144 & 19 & 3,656 & 2 & 59,254 & 21 \\
\hline Not stated & 4,530 & 1 & 17,718 & 2 & 5,679 & 1 & 16,569 & 2 & 1,784 & 1 & 5,500 & 2 & 2,047 & 1 & 5,237 & 2 \\
\hline \multicolumn{17}{|l|}{ Household Composition } \\
\hline Single & 28,965 & 7 & 94,558 & 8 & 36,159 & 7 & 87,364 & 8 & 12,269 & 9 & 29,057 & 9 & 14,351 & 9 & 26,975 & 9 \\
\hline Lone Parent with Children & 11,216 & 3 & 54,668 & 5 & 14,847 & 3 & 51,037 & 5 & 4,168 & 3 & 15,760 & 5 & 4,913 & 3 & 15,015 & 5 \\
\hline Lone Parent no Children under 19 & 13,660 & 3 & 47,117 & 4 & 17,206 & 3 & 43,571 & 4 & 4,335 & 3 & 13,011 & 4 & 5,077 & 3 & 12,269 & 4 \\
\hline Couples with Children & 187,925 & 47 & 432,926 & 38 & 233,282 & 47 & 387,569 & 37 & 55,598 & 40 & 91,137 & 30 & 63,965 & 40 & 82,770 & 29 \\
\hline Couple no Children under 19 & 46,484 & 12 & 141,166 & 12 & 58,615 & 12 & 129,035 & 12 & 16,693 & 12 & 36,716 & 12 & 19,746 & 12 & 33,663 & 12 \\
\hline Couple no Children & 78,710 & 20 & 185,652 & 16 & 97,503 & 19 & 166,859 & 16 & 27,484 & 20 & 50,246 & 16 & 31,805 & 20 & 45,925 & 16 \\
\hline Other Households & 33,019 & 8 & 188,768 & 16 & 42,497 & 8 & 179,290 & 17 & 18,525 & 13 & 72,617 & 24 & 21,550 & 13 & 69,592 & 24 \\
\hline \multicolumn{17}{|l|}{ Means of Travel } \\
\hline Walk & 0 & 0 & 197,622 & 17 & 0 & 0 & 197,622 & 19 & 0 & 0 & 70,080 & 23 & 0 & 0 & 70,080 & 24 \\
\hline Cycle & 0 & 0 & 30,708 & 3 & 0 & 0 & 30,708 & 3 & 0 & 0 & 18,190 & 6 & 0 & 0 & 18,190 & 6 \\
\hline Public transport & 7227 & 2 & 127,782 & 11 & 10,301 & 2 & 124,708 & 12 & 7,935 & 6 & 86,097 & 28 & 12,811 & 8 & 81,221 & 28 \\
\hline Motorcycle & 2511 & 1 & 8,757 & 1 & 3,621 & 1 & 7,647 & 1 & 3,129 & 2 & 2,732 & 1 & 3,674 & 2 & 2,187 & 1 \\
\hline Driving & 287,912 & 72 & 636,747 & 56 & 376,542 & 75 & 548,117 & 52 & 111,508 & 80 & 110,539 & 36 & 127,692 & 79 & 94,355 & 33 \\
\hline Driving - Passenger & 11,351 & 3 & 73,928 & 6 & 14,947 & 3 & 70,332 & 7 & 3,629 & 3 & 12,275 & 4 & 4,359 & 3 & 11,545 & 4 \\
\hline Lorry or van & 90,978 & 23 & 12,414 & 1 & 94,698 & 19 & 8,694 & 1 & 12,871 & 9 & 413 & 0 & 12,871 & 8 & 413 & 0 \\
\hline Work from home & 0 & 0 & 56,897 & 5 & 0 & 0 & 56,897 & 5 & 0 & 0 & 8,218 & 3 & 0 & 0 & 8,218 & 3 \\
\hline
\end{tabular}




\subsection{Logit model results}

This section of the paper examines the characteristics of people who fall above the average emission cap and the average cap lowered by $20 \%$ on both the national and Dublin datasets. Presented in Table 8 are the results of the four models estimated. $\mathrm{R}^{2}$ values are adequately high across all four models, with slightly lower values for the Dublin models which may be due to the smaller dataset used.

The socio-economic group variables are the first set of variables examined. A national cap based on average emissions finds that only three categories of employment would be below a cap. These are higher professionals, lower professionals and non-manual workers are likely to be below a cap. The majority of individuals would be above the cap. When the cap is lowered the results show that manual skilled and semi-skilled workers are likely to fall below the cap. The results for the Dublin models follow the same trends as the national model with the exception of unskilled workers being shown to be below the cap for both of the caps estimated. The gender variable shows that males are more likely to be above the cap across all four models. However the coefficients are lower for Dublin compared to the national average.

The household composition variables are all highly significant across the four models with positive coefficients suggesting the majority of families would be above a cap. The only exception to this finding is in Dublin, where couples with no dependent children are not likely to be above a cap.

The age variable demonstrates a clear generational difference. As would be expected the 15-24 age group has a negative coefficient across all four groups suggesting this group would be below any potential cap. All other age groups are likely to be above a cap with the exception of the 25-34 age group in model 3 . This group has a slightly negative coefficient, however concluding this group would be below a potential cap is not conclusive due to the insignificant $\mathrm{p}$-value of .915. The distance travelled variable is also highly significant across 3 of the 4 groups. Commuters who travel less than $3 \mathrm{~km}$ per trip are highly unlikely to be above any potential cap across all four models. These coefficients become less negative as commuters distance travelled increases suggesting the chance of being above a cap increases with distance travelled. The results for model 4 in this case are inconclusive due to the insignificance of the majority of variables.

As expected, people owning cars or vans are likely to be above any potential cap across all four models. The positive coefficients associated with each variable increase as the number of cars per household increases, increasing the likelihood of being above a cap. The results presented in Table 8 demonstrate the importance of owning a car and driving long distances to work as the main socio-economic characteristics associated with commuters who fell above the cap across all four models. Moreover individuals in certain socio-economic groupings and in the higher age groups were shown to be most negatively impacted by the cap. Under a cap and share scheme it is this section of society that would have to pay a price for higher emissions. 
Table 8 Regression analysis results

\begin{tabular}{|c|c|c|c|c|c|c|c|c|}
\hline & \multirow{2}{*}{\multicolumn{2}{|c|}{$\begin{array}{l}\text { Model 1- } \\
\text { National Cap } \\
\text { Average } \\
\text { Emissions }\end{array}$}} & \multirow{2}{*}{\multicolumn{2}{|c|}{$\begin{array}{l}\text { Model 2- } \\
\text { National Cap } \\
\text { Average } \\
\text { lowered 20\% }\end{array}$}} & \multirow{2}{*}{\multicolumn{2}{|c|}{$\begin{array}{l}\text { Model 3 - } \\
\text { Dublin Cap } \\
\text { Average Emissions }\end{array}$}} & \multirow{2}{*}{\multicolumn{2}{|c|}{$\begin{array}{l}\text { Model } 4- \\
\text { Dublin Cap } \\
\text { Average lowered } \\
20 \%\end{array}$}} \\
\hline & & & & & & & & \\
\hline & & Sig & & Sig & & Sig & & Sig \\
\hline Intercept & -.430 & .000 & -.556 & .000 & -.196 & .182 & .035 & .811 \\
\hline Socio-economic group & & sig & & sig & & sig & & sig \\
\hline Employers and managers & .149 & .000 & .212 & .000 & .027 & .361 & .122 & .000 \\
\hline Higher professional & -.606 & .000 & -.404 & .000 & -.284 & .000 & -.163 & .000 \\
\hline Lower professional & -.270 & .000 & -.089 & .000 & -.132 & .000 & -.030 & .311 \\
\hline Non-manual & -.402 & .000 & -.250 & .000 & -.304 & .000 & -.256 & .000 \\
\hline Manual skilled & .888 & .000 & -.916 & .000 & .667 & .000 & .660 & .000 \\
\hline Semi-skilled & .024 & .314 & -.143 & .000 & .086 & .010 & .052 & .109 \\
\hline Unskilled & .453 & .000 & .427 & .000 & -.145 & .000 & -.232 & .000 \\
\hline Own account workers & 1.756 & .000 & 1.661 & .000 & 1.120 & .000 & 1.105 & .000 \\
\hline Farmers & .526 & .000 & .488 & .000 & .704 & .000 & .743 & .000 \\
\hline Agricultural workers & .342 & .000 & .409 & .000 & .377 & .021 & .198 & .224 \\
\hline $\begin{array}{l}\text { All others gainfully occupied and } \\
\text { unknown }\end{array}$ & Ref & Ref & Ref & Ref & Ref & Ref & Ref & Ref \\
\hline \multicolumn{9}{|l|}{ Gender } \\
\hline Male & .821 & .000 & .676 & .000 & .396 & .000 & .354 & .000 \\
\hline Female & Ref & Ref & Ref & Ref & Ref & Ref & Ref & Ref \\
\hline \multicolumn{9}{|l|}{ Household Composition } \\
\hline Single & 1.03 & .000 & 1.10 & .000 & 1.040 & .000 & 1.086 & .000 \\
\hline Lone Parent with Children & .744 & .000 & .789 & .000 & .735 & .000 & .763 & .000 \\
\hline Lone Parent no Children under 19 & .371 & .000 & .389 & .000 & .238 & .000 & .232 & .000 \\
\hline Couple with Children & .493 & .000 & .496 & .000 & .326 & .000 & .371 & .000 \\
\hline Couple no Children under 19 & .136 & .000 & .086 & .000 & -.152 & .000 & -.127 & .000 \\
\hline Couple no Children & .496 & .000 & .513 & .000 & .414 & .000 & .477 & .000 \\
\hline Other Households & Ref & Ref & Ref & Ref & Ref & Ref & Ref & Ref \\
\hline \multicolumn{9}{|l|}{ Age } \\
\hline $15-24$ & -.431 & .000 & -.606 & .000 & -.794 & .000 & -.754 & .000 \\
\hline $25-34$ & .303 & .010 & .190 & .074 & -0.14 & .915 & .014 & .911 \\
\hline $35-44$ & .410 & .001 & .335 & .002 & .198 & .128 & .268 & .037 \\
\hline $45-54$ & .339 & .004 & .243 & .022 & .161 & .217 & .244 & .058 \\
\hline $55-64$ & .284 & .016 & .198 & .064 & .201 & .124 & .315 & .015 \\
\hline $65-74$ & .210 & .089 & .122 & .277 & .205 & .138 & .386 & .005 \\
\hline $75+$ & Ref & Ref & Ref & Ref & Ref & Ref & Ref & Ref \\
\hline \multicolumn{9}{|l|}{ Distance (KM) } \\
\hline $0-3$ & -7.95 & .000 & -7.56 & .000 & -.7 .210 & .000 & -7.439 & .001 \\
\hline $6-10$ & -6.58 & .000 & -6.56 & .000 & -4.017 & .000 & -3.581 & .028 \\
\hline $11-15$ & -6.55 & .000 & -4.28 & .000 & -2.270 & .000 & -2.018 & .133 \\
\hline $16-20$ & -3.56 & .000 & -1.75 & .000 & -1.255 & .000 & -1.173 & .309 \\
\hline $21-30$ & -1.33 & .000 & -.681 & .000 & -.509 & .000 & -.739 & .478 \\
\hline $31-40$ & -2.46 & .000 & 0.13 & .642 & -.177 & .021 & -.409 & .664 \\
\hline $41+$ & Ref & Ref & Ref & Ref & Ref & Ref & Ref & Ref \\
\hline \multicolumn{9}{|l|}{ Number of Cars } \\
\hline 1 & 2.70 & .000 & 2.83 & .000 & 2.465 & .000 & 2.280 & .000 \\
\hline 2 & 2.28 & .000 & 2.43 & .000 & 2.326 & .000 & 2.166 & .000 \\
\hline 3 & 3.16 & .000 & 3.41 & .000 & 3.261 & .000 & 3.138 & .000 \\
\hline 4 or more & 3.42 & .000 & 3.67 & .000 & 3.504 & .000 & 3.392 & .000 \\
\hline None & Ref & Ref & Ref & Ref & Ref & Ref & Ref & Ref \\
\hline - 2 log-likelihood at convergence & \multicolumn{2}{|c|}{581007.216} & \multicolumn{2}{|c|}{625595.82} & \multicolumn{2}{|c|}{265512.762} & \multicolumn{2}{|c|}{267300.31} \\
\hline $\mathrm{N}$ & \multicolumn{2}{|c|}{$1,438,990$} & \multicolumn{2}{|c|}{$1,438,990$} & \multicolumn{2}{|c|}{422,389} & \multicolumn{2}{|c|}{422,349} \\
\hline Nagelkerke R2 & \multicolumn{2}{|c|}{.780} & .794 & & .657 & & .683 & \\
\hline
\end{tabular}




\section{Conclusions and discussion}

The introduction of a cap and share scheme is one of a number of proposals currently being considering by policymakers to reduce GHG emissions. Ireland, like many other countries, is currently searching for the appropriate policies to reduce emissions from transport and move individuals more sustainable modes of transport. Other policies currently under consideration include the promotion of walking and cycling, the introduction of new public transport services, the electrification of the private car fleet and the introduction of road pricing. One of the benefits that a downstream cap and share scheme policy, as presented in this paper, has over these other policies is that at the it uses tangible and financial benefits and costs to encourage behavioural change. Another benefit of a cap and share scheme is that it would provide individuals with real information on market value of carbon emissions of their trips and this could be used as a tool to encourage the use of alternative modes of transport.

The research presented in this paper provides an indication to the possible impacts of a cap and share scheme. While such a scheme has many benefits, implementing a cap and share scheme like the one proposed in this paper has a number of obstacles and further research needs to be conducted in this area. One of the main technical barriers to implementing this scheme is to obtain a reliable, accurate and cost effective method of collecting information on individuals' trips to measure the emissions per individual. A second large technical barrier is to develop a market personalised emissions trading, on which individuals that go above their allocated allowance are able to purchase unused allocations from others. The creation of such a market and the associated transaction cost also inhibit the development of this policy. Further research on the cost effectiveness of a cap and share scheme would inform the debate in this area and enable policymakers to compare the costs and benefits of this scheme with alternative policy options.

The results presented in this paper provide a useful indicator of the effects of a cap and share scheme in a small country. Larger families and those constrained to using a car as their primary mode of transport are the socio-economic groups most significantly affected by the introduction of a cap. This is particularly true of rural families with no access to alternative forms of transport. Theses equity impacts on which travellers are likely to be worse affected need to be addressed to ensure the scheme is equitable. With this in mind future research will need to determine the potential equity effects of the transfer of wealth created by a cap and share scheme and the merits of introducing a Dublin only cap as opposed to a national cap based on the above findings. Extending the research beyond commuting trips to non-work relating travel would also give a clearer conclusion about which sections of the population would fall above a cap.

\section{Acknowledgements}

The authors would like to thank the Central Statistics Office of Ireland for providing the data for this study. The authors would also like to thank the referees sincerely for their helpful suggestions to improve the original manuscript.

\section{References}

1. Brand, C. and J. M. Preston '60-20 emission'--The unequal distribution of greenhouse gas emissions from personal, non-business travel in the UK. Transport Policy Transport Policy, 17: 9-19, 2010 
2. California Air Reseources Board, Market Advisory Committee to the California Air Resources Board. Recommendations for Designing a Greenhouse Gas Cap-and-Trade System for California. California Air Resources Board, Sacramento, Calif., 2007.

3. Department of Transport, Smarter Travel - A sustainable Transport Future. Department of Transport, Dublin, Ireland, 2009

4. Environmental Protection Agency, Ireland's National Greenhouse Gas Emissions Inventory for 2007, Environmental Protection Agency, Dublin, Ireland, 2008

5. Ellerman, A. D. Tradable Permits for Greenhouse Gas Emissions: A primer with particular reference to Europe. MIT Joint Program Report no. 69, Mass, 2000

6. Fawcett, T. Investigating carbon rationing as a policy for reducing carbon dioxide emissions from UK household energy use. PhD. University College, London, 2005

7. Fleming, D. Tradable Quotas: Using information technology to cap national carbon emissions. European Environment 7(5):139-148., 1997

8. Harwatt, H. Reducing carbon emissions from personal road transportation through the application of a Tradable carbon Permit scheme: Empiracal findings and policy implications from the UK. Institute for Transport Studies, University of Leeds, 2008

9. Millard-Ball, A. Cap-and-Trade: Five Implications for Transportation Planners. 88th Annual Meeting of the Transportation Research Board. Washington D.C, 2008

10. Millard-Ball, A. Municipal Mobility Manager: New Transportation Funding Stream from Carbon Trading? In Transportation Research Record: Journal of the Transportation Research Board, No. 2079, Transportation Research Board of the National Academies, Washington, D.C., 2008, pp. 53-61.

11. Niemeier, D., G. Gould, A. Karner, M. Hixson, B. Bachmann, C. Okma, Z. Lang and D. Heres Del Valle. Rethinking downstream regulation: California's opportunity to engage households in reducing greenhouse gases. Energy Policy 36(9):3436-3447, 2008

12. Raux, C. and Marlot, G. A system of tradable CO2 permits applied to fuel consumption by motorists. Transport Policy, 12, 255-265, 2005

13. Sustainable Development Council, A study in Personal Carbon Allocation: Cap and Share. Sustainable Development Council, Dublin, Ireland, 2008

14. Starkey, R., K. Anderson. Domestic Tradable Quotas: A policy instrument for reducing greenhouse gas emissions from energy use. Tyndall Centre for climate change Research, Technical report 39, 2005

15. Tietenberg, T. The tradable permits approach to protecting the commons: what have we learned. Presented at the 1st CATEP Conference: 'Trading scales: linking industry, local/regional, national and international emission trading schemes', Fondazione Eni Enrico Mattei, Venice, 3-4 December, 2001 
16. Wadud, Z. Personal carbon permits for road transport: Why, why noy and who wins? Transportation Research Part A: Policy and Practise, In Press, 2010

17. Walsh, C., P Jakeman, et al. A comparison of carbon dioxide emissions associated with motorised transport modes and cycling in Ireland. Transportation Research Part D: Transport and Environment, 13(6) : 392-399, 2008

18. Washinton, S., Karlaftis, M. \& Mannering, F. Statistical and econometric methods for transportation data analysis, CRC Press, 2003 